\title{
Organ-, inflammation- and cancer specific transcriptional fingerprints of pancreatic and hepatic stellate cells
}

\author{
Mert Erkan', Nadine Weis², Zheng Pan'1, Christian Schwager2, Tamar Samkharadze1, Xiaohua Jiang1', Ute Wirkner², \\ Nathalia A Giese³, Wilhelm Ansorge2, Jürgen Debus², Peter E Huber², Helmut Friess' ${ }^{2}$, Amir Abdollahi*2,4,5 and \\ Jörg Kleeff*+1,4
}

\begin{abstract}
Background: Tissue fibrosis is an integral component of chronic inflammatory (liver and pancreas) diseases and pancreatic cancer. Activated pancreatic- (PSC) and hepatic- (HSC) stellate cells play a key role in fibrogenesis. To identify organ- and disease-specific stellate cell transcriptional fingerprints, we employed genome-wide transcriptional analysis of primary human PSC and HSC isolated from patients with chronic inflammation or cancer.

Methods: Stellate cells were isolated from patients with pancreatic ductal adenocarcinoma $(n=5)$, chronic pancreatitis $(n=6)$, liver cirrhosis $(n=5)$ and liver metastasis of pancreatic ductal adenocarcinoma $(n=6)$. Genome-wide transcriptional profiles of stellate cells were generated using our 51 K human cDNA microarray platform. The identified organ- and disease specific genes were validated by quantitative RT-PCR, immunoblot, ELISA, immunocytochemistry and immunohistochemistry.

Results: Expression profiling identified 160 organ- and 89 disease- specific stellate cell transcripts. Collagen type 11a1 (COL11A1) was discovered as a novel PSC specific marker with up to 65-fold higher expression levels in PSC compared to HSC ( $p<0.0001)$. Likewise, the expression of the cytokine CCL2 and the cell adhesion molecule VCAM1 were confined to HSC. PBX1 expression levels tend to be increased in inflammatory-vs. tumor-stellate cells. Intriguingly, tyrosine kinase JAK2 and a member of cell contact-mediated communication CELSR3 were found to be selectively upregulated in tumor stellate cells.

Conclusions: We identified and validated HSC and PSC specific markers. Moreover, novel target genes of tumor- and inflammation associated stellate cells were discovered. Our data may be instrumental in developing new tailored organ- or disease-specific targeted therapies and stellate cell biomarkers.
\end{abstract}

\section{Introduction}

Emerging body of data suggest a critical role for stellate cells in the pathophysiology of pancreatic cancer and chronic inflammatory diseases [1-5]. Hepatic stellate cells (HSC) were first described by Karl von Kupffer in 1876, however similar cells in the pancreas were first observed

\footnotetext{
* Correspondence: Amir.Abdollahi@tufts.edu, kleeff@gmx.de²

Department of Radiation Oncology, German Cancer Research Center (DKFZ) and University of Heidelberg, Heidelberg, Germany

2 Department of General Surgery, Technische Universität München, Munich, Germany

† Contributed equally

Full list of author information is available at the end of the article
}

in 1980s [1,3,6]. In 1998 Bachem and Apte isolated and cultured pancreatic stellate cells (PSC) [7,8]. Morphologic, functional and gene expression studies revealed that PSC resemble HSC characteristics and therefore may possibly share a common origin $[3,9]$. However, the origin of stellate cells is still controversially debated. Mesenchymal $[10,11]$, endodermal $[12,13]$ as well as neuroectodermal origins [14-16] are suggested. Further, it is postulated that in the diseased organ, stellate cells are transformed from their quiescent precursors, or recruited from local fibroblasts, bone marrow derived cells or generated via epithelial-mesenchymal transformation $[1,3,17]$. 
HSC represent 5-8\% of all human liver cells and reside in the space of Disse [1]. In contrast to quiescent HSC, activated HSC lack cytoplasmic lipid droplets containing retinyl esters and long cytoplasmic processes. Their activation or trans-differentiation is regulated by paracrine and autocrine loops of growth factors which are associated with pathological conditions such as liver injury, cirrhosis and cancer [1,2]. Stellate cell over-activity can severely impair organ function due to excessive contraction and abundant extracellular matrix protein deposition. Moreover, it is becoming clearer that myofibroblasts found in the activated stroma of epithelial tumors significantly impact tumor behavior [5,18]. Tumor-stroma interactions influence both the progression of cancer and tumor responses to cancer therapies [4,5,18-21]. Since conventional therapies are far from cure, new targeted therapies appear as promising alternatives or adjuncts [22]. Indeed, the tumor microenvironment and the desmoplastic reaction observed in pancreatic ductal adenocarcinoma (PDAC) have attracted enormous scientific attention and emerged as a critical therapeutic target $[19,23,24]$.

To selectively and specifically target HSC or PSC in chronic inflammatory diseases or in cancer, a better molecular characterization of these cells is required. In an attempt to identify organ- and disease-specific transcripts, we isolated stellate cells from a total of 22 patients with primary PDAC, chronic pancreatitis, liver cirrhosis, and liver metastasis of PDAC. Genome-wide transcriptional analysis was employed and novel candidate tumor-, inflammation- or organ-specific stellate cell genes were identified and validated in the tissues of these patients by real time quantitative RT-PCR, immunohistochemistry, immunocytochemistry, ELISA and immunoblot analyses.

\section{Materials and methods \\ Pancreatic tissues and human pancreatic stellate cell cultivation}

The use of human material for the analysis was approved by the local ethics committee of the University of Heidelberg, Germany, and written informed consent was obtained from all patients. Sterile tissues were obtained immediately after surgical resection from five patients with PDAC, six patients with chronic pancreatitis (CP), five patients with liver cirrhosis (LC) that underwent liver transplantation, and six patients with liver metastasis (LM) of pancreatic cancer. During tissue collection, freshly removed samples were either snap frozen in liquid nitrogen and stored at $-80^{\circ} \mathrm{C}$ for protein and DNA extraction or preserved in RNA-later solution for future RNA extraction. A portion of the samples was also fixed in $4 \%$ parafomaldehyde solution for 12-24 $\mathrm{h}$ and then embedded in paraffin for histological analysis. Human stellate cell isolation and cultivation were performed under ster- ile conditions for all cell types by using the outgrowth method as described initially by Bachem et al. [8]. Briefly; passage-1 was described as the first lot of cells growing out from fibrotic blocks of pancreatic tissues seeded in 10 $\mathrm{cm}$ Petri dishes. To prevent bias, the number of blocks was kept constant (30 blocks with 2-3 mm diameter/per $75 \mathrm{~cm}^{2}$ ). Passage-2 is a 1:2 division of these cells into two new T75 $\mathrm{cm}^{2}$ flasks. When passage- 2 cells reached confluency, they were aliquoted and frozen. All cells used were passage- 3 after thawing a clone of frozen passage- 2 . Purity of stellate cells was routinely checked by immunocytochemistry and immunofluorescence analyses (Additional file1). All passages used were controlled and no morphologically different subpopulation was detected.

\section{Total RNA isolation}

To prevent passage dependent variations, third passages of PSC and HSC were used for all analyses. Total RNA from $80 \%$ confluent stellate cells in $10 \mathrm{~cm}$ Petri dishes was isolated by organic extraction with the phenolic Trizol reagent as described [25]. The Agilent 2100 Bioanalyzer (Agilent Technologies Inc. Santa Clara, CA) was used for the quality control of the isolated total RNA and amplified RNA (aRNA) by capillary electrophoretic separation [26].

\section{Genome-wide expression profiling}

Genome-wide expression profiling was done using $51 \mathrm{~K}$ Human Unigene III cDNA microarrays. The microarrays were designed, generated, and hybridized as described previously $[24,26,27]$. Each sample was hybridized against Human Universal Reference Total RNA (\# 636538, BD Clontech, Heidelberg, Germany). Expression profiling was performed as previously described with minor modifications [24,26,27]. Linear amplification from $2 \mu \mathrm{g}$ total RNA was performed using the "MessageAmp II aRNA Amplification Kit" (Ambion, \#1751). From amplified RNA, $5 \mu \mathrm{g}$ were used for indirect labeling by incorporation of aminoallyl modified nucleotides and chemical attachment of free reactive fluorescent Cy3- or Cy5-dye (Atlas Glass fluorescent labelling kit, BD Biosiences Catalogue \#K1037-1; Cy5-dye, Cy3-dye, GE Healthcare UK Limited, \#Q15108, \#Q13108). Corresponding Cy3- and Cy5- labeled probes and competitor DNA (5 $\mu \mathrm{g}$ human Cot-DNA, Invitrogen; $5 \mu \mathrm{g}$ poly-dA, Amersham) were combined, diluted in hybridization buffer to a final volume of $80 \mu \mathrm{l}$ (50\% Formamide, $6 \times$ SSC, $0.5 \%$ SDS, $5 \times$ Denhards), and denatured for $5 \mathrm{~min}$ at $95^{\circ} \mathrm{C}$ prior to hybridization. Prehybridization was performed at $42^{\circ} \mathrm{C}$ for $20 \mathrm{~min}$ in $6 \times$ SSC, $0.5 \%$ SDS, $1 \%$ BSA. Slides were rinsed in $\mathrm{H}_{2} \mathrm{O}$ and spotted probes were denatured by incubating the slide for $2 \mathrm{~min}$ in $90^{\circ} \mathrm{C}_{2} \mathrm{O}$. Hybridization probe was added and static hybridization performed at $42^{\circ} \mathrm{C}$ for $16 \mathrm{~h}$. Excess of probe was removed by washing in 
$2 \times \mathrm{SSC}, 0.5 \% \mathrm{SDS}$ at $42^{\circ} \mathrm{C}$ for $5 \mathrm{~min}$, then in $0.2 \times \mathrm{SSC}$, $0.5 \% \mathrm{SDS}$ at $42^{\circ} \mathrm{C}$ for $15 \mathrm{~min}$ and finally in isopropanol for 30s at RT. Slides were scanned with Agilent Microarray Scanner and image processing was done using the "Chipskipper" software. Data were stored in MO-MEX database Bloader that enables direct submission of large batches of MIAME complaint expression profiling data to the ArrayExpress database. Microarray data are available online at ArrayExpress http://www.ebi.ac.uk/arrayexpress under the accession no. E-TABM-625.

\section{Statistical analysis of the microarray data}

Generation of expression matrices, data annotation, filtering, and processing were done using TableButler software package http://www.oncoexpress.de/software/ tablebutler. All microarray statistics including $t$-test with permutation analysis, Pavlidis template matching (PTM), and cluster analysis were done using the Java based software package TIGR MultiExperiment Viewer (TMEV) version $3.01 \mathrm{http://www.tm4.org/mev.html.} \mathrm{Genes} \mathrm{were}$ defined as differentially expressed between two sets of samples if a two-class permutation based $t$-test (number of permutations $=1000$ ) yielded a $\mathrm{p}$-value of less than 0.05 after standard Bonferroni correction for multiple hypothesis testing. Subsequently, regulated genes were sorted by hierarchical clustering (HCL). PTM allows the specification of a template expression profile for a gene by designating relative gene expression ratios for each condition. The data sets are searched for matches to this template, i.e. for the specific expression pattern. Gene expression data were filtered for genes that matched each template based on a Pearson correlation coefficient $r \geq$ 0.70 . The obtained gene expression profiles were visualized as heatmaps.

\section{Real time quantitative PCR}

All reagents and equipment for mRNA/cDNA preparation were purchased from Roche Applied Science Diagnostics (Mannheim, Germany). mRNA extractions were prepared by automated isolation using the MagNA Pure LC instrument and isolation kit I. cDNA was prepared using the first-strand cDNA synthesis kit (AMV) according to the manufacturer's instructions. Real-time PCR was performed with the Light Cycler Fast Start DNA SYBR Green kit. All primers were obtained from SearchLC (Heidelberg, Germany). The calculated number of specific transcripts was normalized to 10,000 copies of the housekeeping gene PPIB (peptidylprolyl isomerase $B$, also known as cyclophilin $B$ ), and expressed as number of copies per $\mu \mathrm{l}$ of input cDNA. Statistical comparisons were made by Mann-Whitney U test. A P-value less than $5 \%$ was regarded as significant.

\section{Immunohistochemistry and immunocytochemistry analyses}

IHC was performed as described before [28]. Antibodies used and the dilution ratios are shown in Table 1. Immunocytochemistry analysis was performed using a previously described protocol [29].

\section{Immunoblot analysis and densitometry}

To keep passage dependent variations at minimum, third passages of PSC and HSC were used for analysis. Stellate cells were grown in Petri dishes until 80\% confluency under standard conditions. Protein extraction was carried out as published before [28]. Immunoblot analyses and the densitometric analysis of the blots were done as described previously [30]. Antibodies used and the appropriate dilution are shown in Table 1. Graphic results are expressed after normalization to the housekeeping

Table 1: The antibodies used and the appropriate dilutions.

\begin{tabular}{lcccc}
\hline & COL11a1 & VCAM1 & CELSR3 & Pbx1 \\
\hline Company & $\begin{array}{c}\text { Santa Cruz } \\
\text { (sc-68853) }\end{array}$ & $\begin{array}{c}\text { Santa Cruz } \\
\text { (sc-8304) }\end{array}$ & $\begin{array}{c}\text { Abcam (ab12958) } \\
\text { Santa Cruz (sc-46849) }\end{array}$ & $\begin{array}{c}\text { Abcam } \\
\text { (ab12001) }\end{array}$ \\
\hline Host & Rabbit & Rabbit & Rabbit (Abcam) & Rabbit \\
\hline Immunohistochemistry & $1: 500$ & Santa Cruz) & $1: 100$ (Abcam) & $1: 100$ \\
\hline Immunoblot & na & $1: 200$ & $1: 250$ (Santa Cruz) & $1: 100$ \\
\hline Immunocytochemistry & $1: 100$ & $1: 250$ & Na & na \\
\hline na: not applicable & & $\mathrm{Na}$ & &
\end{tabular}


gene GAPDH as percent change of the appropriate control.

\section{ELISA}

Cells were grown in 10-cm plates until $80 \%$ confluence. Serum free medium was kept on the cells for $48 \mathrm{~h}$. Supernatants and total cell lysates were extracted and frozen at $-80^{\circ} \mathrm{C}$ until use. For the quantification of CCL2, a commercially available ELISA kit (Human MCP-1 ELISA, 555179, BD Biosciences, Heidelberg, Germany) was used according to the manufacturers' recommendations.

\section{Results}

\section{Evaluation of gene expression profiles}

Morphology and purity of stellate cells was routinely checked by immunocytochemistry (Additional file1). In order to identify organ and disease specific transcriptome signatures of stellate cells, a microarray analysis was made (Figure 1, Figure 2). The obtained gene expression profiles were visualized as heatmaps (Figure 3, Figure 4). Red signifies high gene expression, while black signifies intermediate gene expression and green signifies low gene expression of the corresponding gene compared to the reference, respectively. Each row represents one gene, each column represents one sample. The dendrograms on the left side of the heat maps define how the genes cluster after applying hierarchical cluster analysis (average linkage). Expressions of genes are expressed using $\log 2$ ratios, where the $+/$ - sign indicates which channel had the higher intensity. Hence, an expression ratio of +2 represents a 4-fold up-regulation of a gene under condition A compared to this gene under condition B, an expression ratio of -2 represents a 4 -fold down-regulation.

\section{Organ specific profile}

A total of 160 annotated genes were identified as differentially expressed between pancreas and liver derived stellate cells. To obtain a clear and well-defined matrix, these genes were compared as: downregulated in pancreatic stellate cells in comparison to hepatic stellate cells $(n=$ 80 , Figure $3 \mathrm{~B}$ ) or upregulated in pancreatic stellate cells in

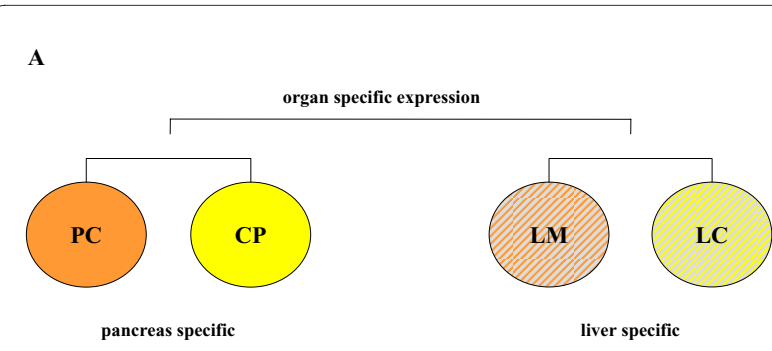

Figure 1 Schematic expression of the hypothesis: Organ specific expression profile (pancreas vs. liver) of stellate cells.

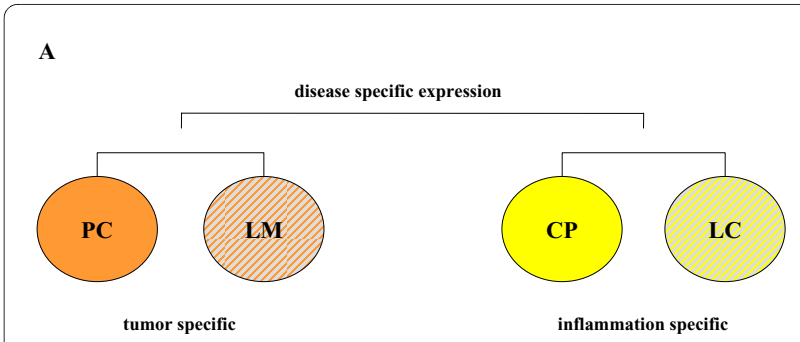

Figure 2 Schematic expression of the hypothesis: Disease specific expression profile (tumor vs. inflammation) of stellate cells

comparison to hepatic stellate cells $(\mathrm{n}=80$, Figure 3C). A group of selected genes are presented in Table 2. Significantly different genes in each group with high differential expression ratios were further analyzed by quantitative real time PCR, immunoblotting, immunocytochemistry and immunohistochemistry in all patients.

\section{Pancreatic stellate cell specific genes}

In this group, collagen type XI alpha 1 (Col11a1) was the most specific gene with a 13.74-fold upregulation in PSC compared to HSC. In concordance with the array data, Col11a1 was highly pancreas specific with its average mRNA expression being 65 -fold $(\mathrm{p}<0.0001)$ higher in the PSC compared to that of HSC as determined by qRT-PCR (Figure 5A). Since there was no suitable antibody for immunoblot analysis, the expression of Col11a1 in tissues and in cultured stellate cells was evaluated by immunohistochemistry and immunocytochemistry. In all patients, PSC showed a specific staining while HSC remained Col11a1 negative by immunohistochemistry. Co-localization of alpha-smooth muscle actin (red) and Col11a1 (green) in stellate cells in pancreatic tissues is shown by immunofluorescence analysis (Figure 5B). There was also a weak staining in pancreatic acini and hepatocytes (Figure $5 \mathrm{C}-\mathrm{H})$. Verification of Col11a1 protein expression in cultured stellate cells by immunocytochemistry showed also a PSC specific staining (Figure 6).

\section{Hepatic stellate cell specific genes}

In this group, some genes showed a high HSC specificity. Vascular cell adhesion molecule 1 (VCAM1) was 5.05fold upregulated in HSC compared to PSC and chemokine (C-C motif) ligand 2 (CCL2) was 2.96-fold upregulated in HSC compared to PSC. In line with the microarray data compared to their average expressions in PSC, VCAM1 and CCL2 mRNA expressions were 5.66fold $(\mathrm{p}=0.0016)$ and 2.28 -fold $(\mathrm{p}=0.0020)$ higher in HSC as determined by qRT-PCR, respectively (Figure 7A \& Figure 8D). Next, to quantify the protein expression in vitro, cell lysates of cultured human stellate cells $(n=4$ per pathology) were analyzed by immunoblotting or ELISA. Protein expression of VCAM1 in cultivated stel- 


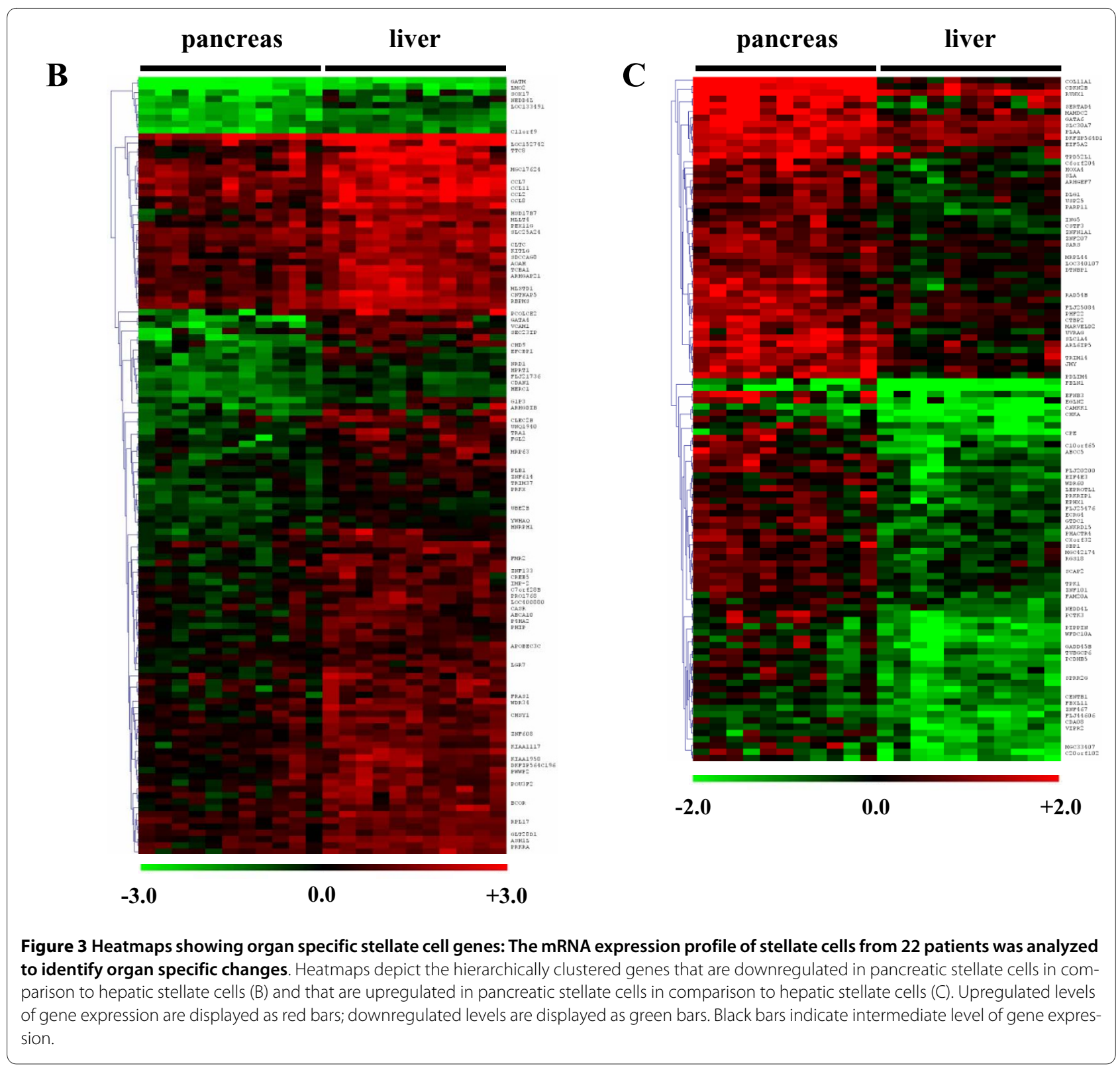

late cells mirrored its mRNA expression. Densitometric analysis of samples showed a 4.71-fold $(\mathrm{p}=0.028)$ higher expression in HSC compared to that of PSC (Figure 7B). Since there was no suitable antibody for immunoblot analysis for CCL2, quantification was made by ELISA. Similar to VCAM1 expression, CCL2 also showed a HSC specific expression irrespective of the pathology (3.15fold, $p=0.024$, Figure $8 E$ ). In the last step, we verified the localization of these proteins in human tissues. Liver cirrhosis tissues were probed with alpha-smooth muscle actin (Figure 8A) or VCAM-1 (Figure 8B). Co-localization of alpha-smooth muscle actin (red) and VCAM-1 (green) in stellate cells (orange) in hepatic tissues is shown by immunofluorescence analysis (Figure 8C). All patients showed various degrees of VCAM1 expression.
Although immunohistochemistry showed specific staining in stellate cells, there was no obvious organ predilection. In addition to stellate cells, pancreatic cancer cells, hepatocytes and some inflammatory cells were also positive for VCAM1 (Figure 7C-H).

\section{Disease specific profile}

Microarray analysis further identified a total of 89 annotated genes as differentially expressed between stellate cells derived from inflammatory and malignant conditions (Figure 2). To obtain a clear and well-defined matrix, these genes were sorted by two given expression profiles as: downregulated in stellate cells of inflamed tissues compared to stellate cells of tumor tissues $(n=25$, Figure 4B) or upregulated in inflamed tissue compared to 


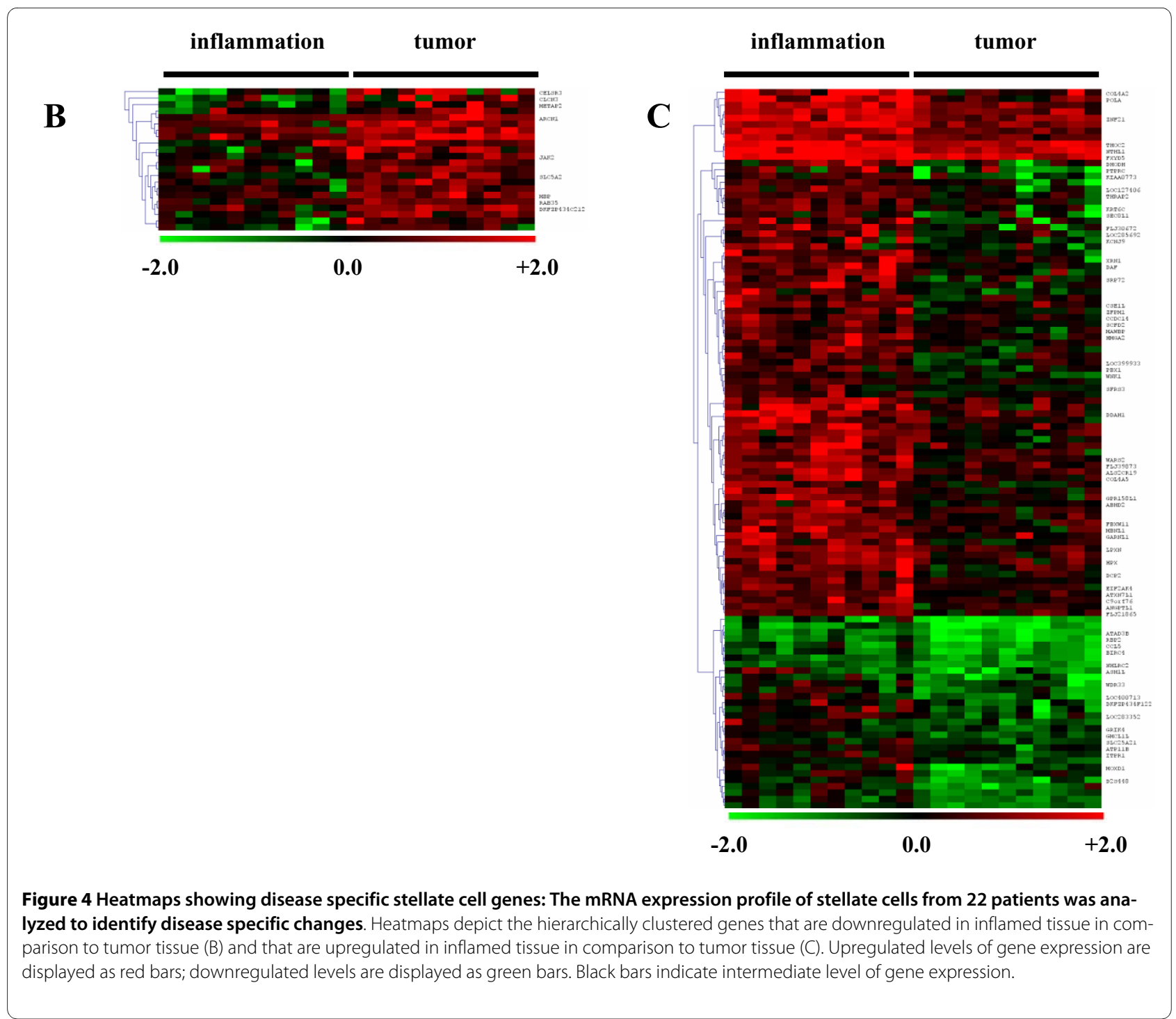

tumor tissues ( $n=64$, Figure $4 C$ ). Significantly different genes in each group with high differential expression ratios were further analyzed by quantitative real time PCR, immunoblotting, immunocytochemistry and immunohistochemistry in all patients. A group of selected genes are presented in Table 3.

\section{Tumor specific genes}

Microarray analysis showed that some genes displayed a cancer specific pattern irrespective of the organ the stellate cells were derived from. For example, cadherin EGF LAG seven-pass G-type receptor 3 (CELSR3) was 3.04fold upregulated in tumor associated stellate cells compared to inflammation associated stellate cells. Similarly, its mRNA expression was $123 \%$ higher $(\mathrm{p}=0.004)$ in the cancer associated stellate cells as determined by qRTPCR (Figure 9A). By immunoblot analysis, CELSR3 protein was expressed at $83 \%$ higher levels $(p=0.030)$ in tumor related stellate cells compared to that of inflammation related stellate cells (Figure 9B). There was also a disease specific expression of CELSR3 expression in tissues (Figure 9C-F). While hepatocytes were mostly unstained some pancreatic acini and pancreatic cancer cells were also positive for CELSR3.

\section{Inflammation specific genes}

In the microarray analysis, pre-B-cell leukemia transcription factor 1 ( $\mathrm{Pbx} 1$ ) was 1.7 -fold upregulated in inflammation associated stellate cells compared to tumor associated stellate cells. Although the differences did not reach statistical significance, Pbx1 expression was also $98 \%$ higher $(\mathrm{p}=0.107)$ in inflammation associated stellate cells as determined by qRT-PCR (Figure 10A). Similarly, the protein expression of Pbx1 was also 64\% higher in stellate cells derived from inflammatory pathologies compared to that of tumor derived stellate cells $(p=0.70$, Fig- 
Table 2: A group of highly differentially expressed genes between liver and pancreas stellate cells are shown.

\begin{tabular}{|c|c|c|}
\hline Gene Name Description & RefSeq ID & Fold-change \\
\hline \multicolumn{3}{|l|}{ ORGAN-SPECIFIC DIFFERENCES IN GENE EXPRESSION } \\
\hline \multicolumn{3}{|l|}{ Liver specific transcripts (High in HSC compared to PSC) } \\
\hline VCAM1 vascular cell adhesion molecule 1 & NM_001078 & 5.05 \\
\hline PCOLCE2 procollagen C-endopeptidase enhancer 2 & NM_013363 & 4.69 \\
\hline SOX17 SRY (sex determining region Y)-box 17 & NM_022454 & 3.54 \\
\hline GATA4 GATA binding protein 4 & NM_002052 & 3.41 \\
\hline TTC8 tetratricopeptide repeat domain 8 & NM_144596 & 3.02 \\
\hline $\mathrm{CCL} 2$ chemokine ( $\mathrm{C}-\mathrm{C}$ motif) ligand 2 & NM_002982 & 2.96 \\
\hline SEC23IP SEC23 interacting protein & NM_007190 & 2.92 \\
\hline CCL11 chemokine (C-C motif) ligand 11 & NM_002986 & 2.85 \\
\hline \multicolumn{3}{|l|}{ Pancreas specific transcripts (High in PSC compared to HSC) } \\
\hline COL11A1 collagen, type XI, alpha 1 & NM_080629 & 13.74 \\
\hline EFNB3 ephrin-B3 & NM_001406 & 4.83 \\
\hline SERTAD4 SERTA domain containing 4 & NM_019605 & 4.29 \\
\hline EGLN2 egl nine homolog 2 (C. elegans) & NM_053046 & 4.00 \\
\hline CDKN2B cyclin-dependent kinase inhibitor 2B ( $\mathrm{p} 15$, inhibits CDK4) & NM_004936 & 3.56 \\
\hline CPE carboxypeptidase E & NM_001873 & 3.54 \\
\hline CHKA choline kinase alpha & NM_001277 & 3.31 \\
\hline FBLN1 fibulin 1 & NM_001996 & 3.26 \\
\hline
\end{tabular}

ure 10B). Although partly discrepant with the immunoblot analysis, this tendency was also visible by immunohistochemistry analysis (Figure 10C-F). In addition to stellate cells, tubular complexes in pancreatic tissues and bile ducts in the liver parenchyma also displayed some $\mathrm{Pbx} 1$ positivity.

\section{Discussion}

Here we report the identification of novel tumor stellate cell specific genes and proteins. In addition, hepatic vs. pancreatic stellate cell specific transcripts were discovered. The mRNA and protein expression levels of candidate genes identified by genome-wide transcriptional 


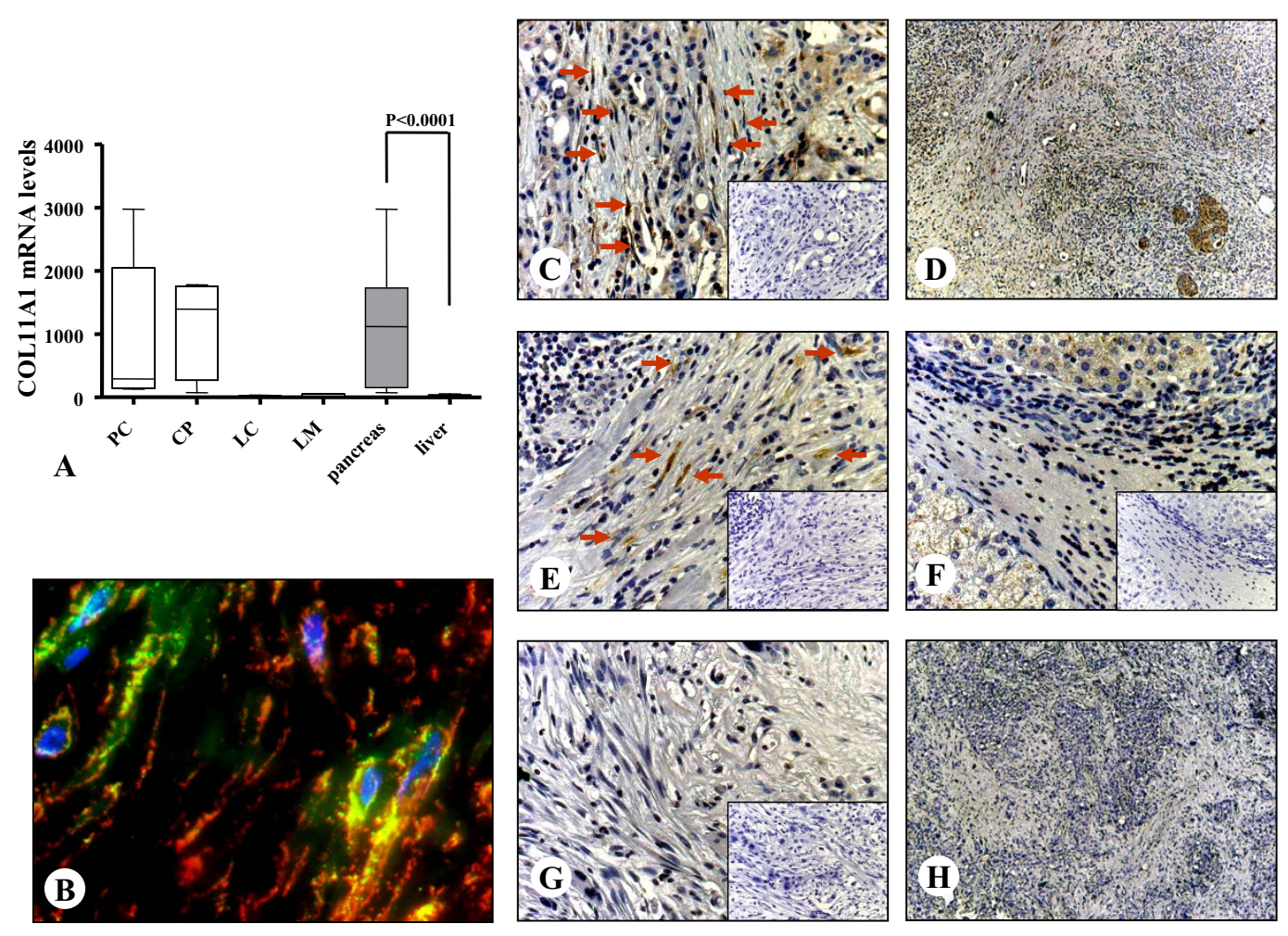

Figure 5 Quantitative mRNA analysis of Collagen11a1 and its localization in tissues and cultured stellate cells. Quantitative real-time PCR (A) was performed with the Light Cycler Fast Start DNA SYBR Green kit. The organ specific expression of Collagen 11 a1 is depicted in the last two columns of the graph. Double-staining and ex vivo immunofluorescence analysis is used to evaluate the colocalization (orange) of the typical stellate cell marker a-SMA (red) and Collagen11a1 (green) in activated stellate cells of pancreatic cancer tissues (B, 630X). Tissues of primary pancreatic ductal adenocarcinoma (C, 200X, D, 50X), chronic pancreatitis (E, 200x), liver cirrhosis ( $F, 200 x)$ and liver metastasis of pancreatic ductal adenocarcinoma (G, 200X, $\mathrm{H}, 50 \times$ ) were immunostained with a specific antibody against Collagen11a1. Negative controls are shown as insets. Arrows show the stellate cells/ myofibroblasts in the fibrotic parts of the tissues.
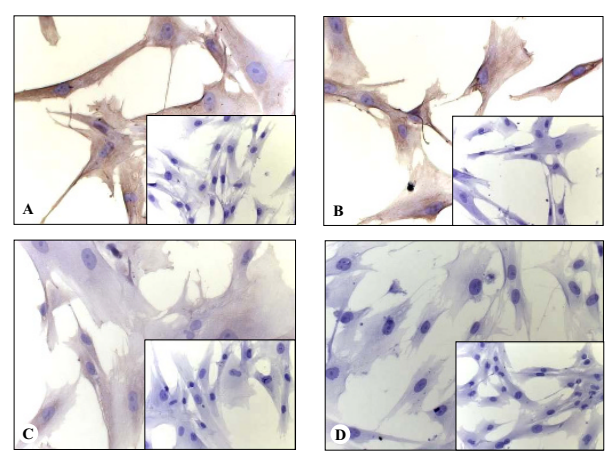

Figure 6 Expression analysis of Collagen 11 a 1 in cultivated stellate cells: Immunocytochemistry was used to analyze Collagen $11 \mathrm{a} 1$ expression in cultured stellate cells derived from tissues of primary pancreatic ductal adenocarcinoma $(A, 400 \times)$, chronic pancreatitis $(B, 400 x)$, liver cirrhosis $(C, 400 x)$ and liver metastasis of pancreatic ductal adenocarcinoma ( $D, 400 \times)$. Cells were seeded on Teflon covered slides, fixed, permeabilized and immunostained with a specific antibody against collagen type 11a1. Negative controls are shown as insets. analysis were confirmed by qRT-PCR, ELISA and Immunoblot analyses. The specific expression pattern of the candidate proteins was further assured in-vitro by immunocytochemistry of isolated stellate cells and ex-vivo by immunohistochemistry of formalin fixed paraffin embedded tissues. The identified molecular fingerprint of stellate cells might be instrumental in development of novel biomarkers and rational design of therapeutic strategies aiming to selectively target cancer or inflammation associated stellate cells. One drawback of this study is the absence of a third comparator, namely stellate cells from the normal pancreas and liver. However, stellate cells from the normal pancreas do not grow efficiently when propagated by the outgrowth method. Neither could stellate cells from fibrotic tissues like chronic pancreatitis and pancreatic cancer be efficiently propagated by collagenase digestion and centrifugation. The yield of the latter method is very low in comparison to the outgrowth method. Therefore the authors have decided to use only one stellate cell propagation method (outgrowth) to prevent bias that may result from differences in methodol- 
A
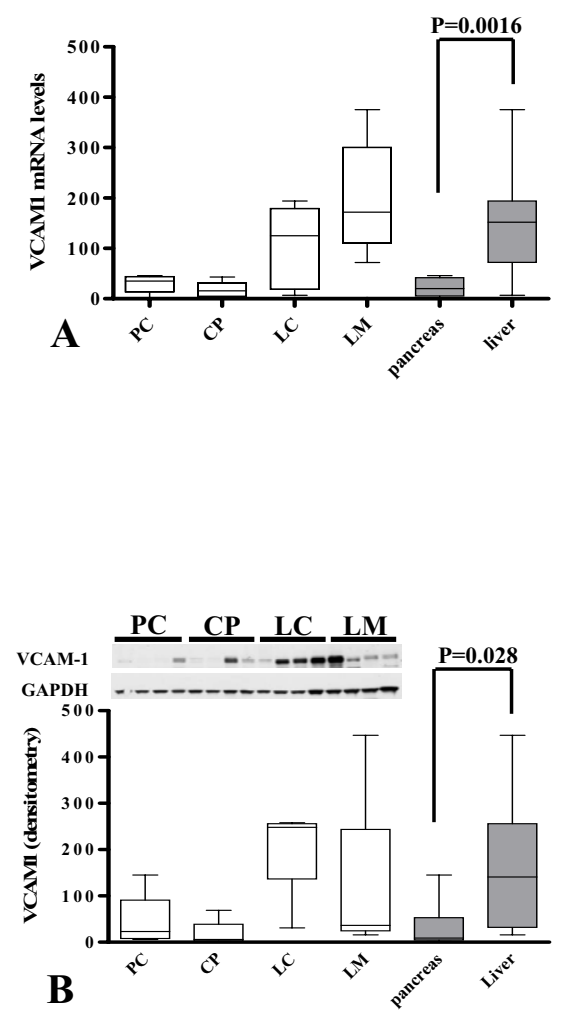
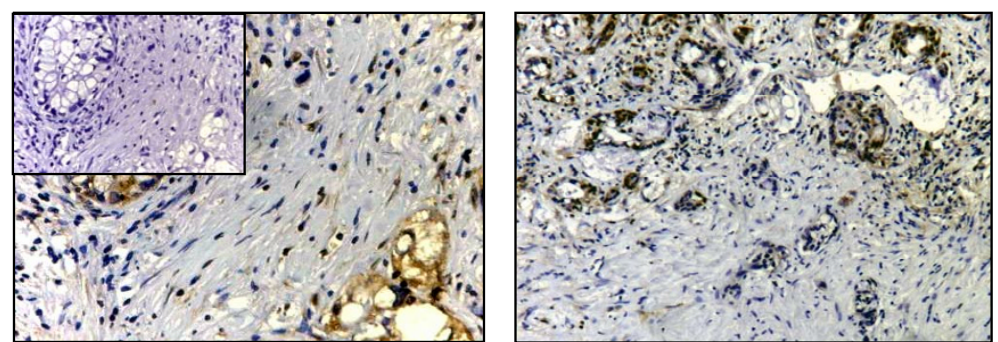

C

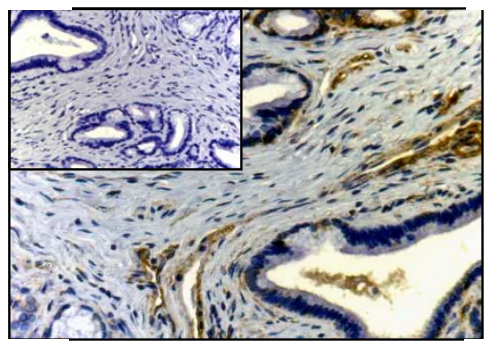

$\mathbf{E}$

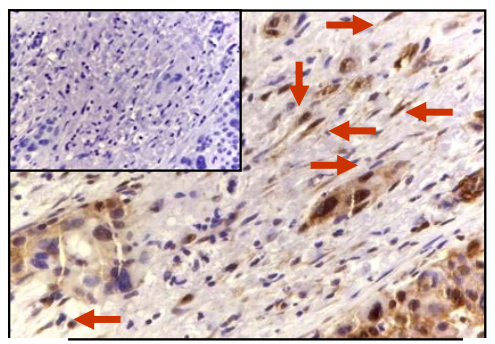

G
D

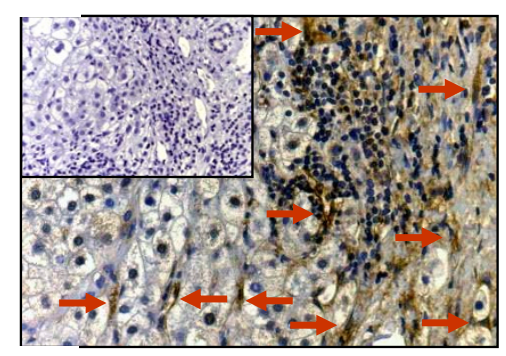

F

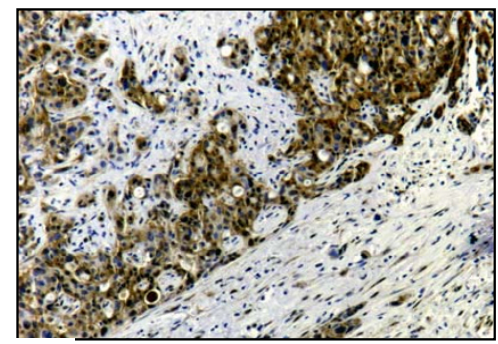

H

Figure 7 Quantitative mRNA and protein expression analysis of VCAM1 and its localization in tissues. Quantitative real-time PCR (A) was performed with the Light Cycler Fast Start DNA SYBR Green kit. Densitometric analysis of immunoblots (B) were performed using the ImageJ program provided by the National Institutes of Health. Optic densities were corrected for the individual background noise and the matching equal loading densities. Each column represents one patient. For each entity, stellate cells from four different patients were evaluated. The organ specific expression of VCAM1 is depicted in the last two columns of each graph. Tissues of primary pancreatic ductal adenocarcinoma (C, 200X, D,50X), chronic pancreatitis $(E, 200 x)$, liver cirrhosis $(F, 200 x)$ and liver metastasis of pancreatic ductal adenocarcinoma $(G, 200 x, H, 50 x)$ were immunostained with a specific antibody against VCAM1. Arrows show the stellate cells in the fibrotic parts of the tissues. Negative controls are shown as insets.

ogy. As a trade-off, a comparator (normal stellate cells) could not be used.

Among the here identified tumor stellate cell specific genes, JAK2 and CELSR3 pose interesting targets for developing therapeutic strategies. Aberrant JAK2 signaling has been linked to myeloproliferative disorders such as polycythemia vera and chronic myelogenous leukemia $[31,32]$. Small molecular inhibitors of JAK2 signaling have already entered clinical trials. Therefore the role of JAK2 overexpression in PSC of PDAC tumors remains to be functionally elucidated. Upregulation of CELSR3 in tumor PSC could also provide a potential druggable target since the protein encoded by this gene is located at the plasma membrane and has intriguing signaling capabilities [33]. CELSR3 is a member of the flamingo protein subfamily which is part of the cadherin superfamily. The flamingo cadherins have nine cadherin domains, seven epidermal growth factor-like repeats and two laminin A G-type repeats in their ectodomain [34]. It is postulated that these proteins are receptors involved in contactmediated communication, with cadherin domains acting as homophilic binding regions and the EGF-like domains involved in cell adhesion and receptor-ligand interactions. Together, these data suggest an important role for CELSR3 in tumor stellate cells that warrants further investigation.

Recent studies have reported differential regulation of genes in murine and human stellate cells throughout their activation process and under certain drug therapies. Although these studies provide valuable information, a careful interpretation of their data is warranted. First, murine stellate cells may not reflect the situation in humans due to interspecies differences. Second, stellate cells show a great variance depending on the donor, 


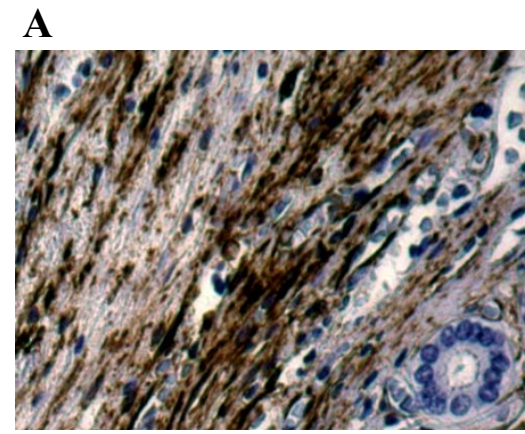

B

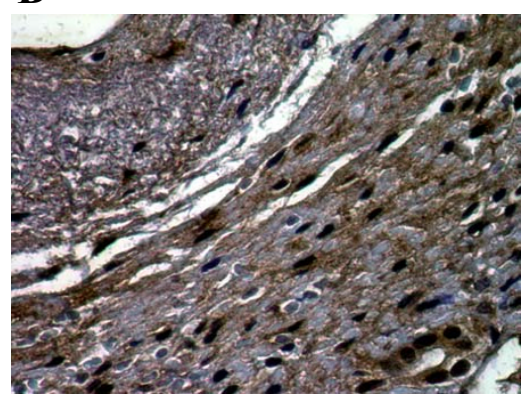

C

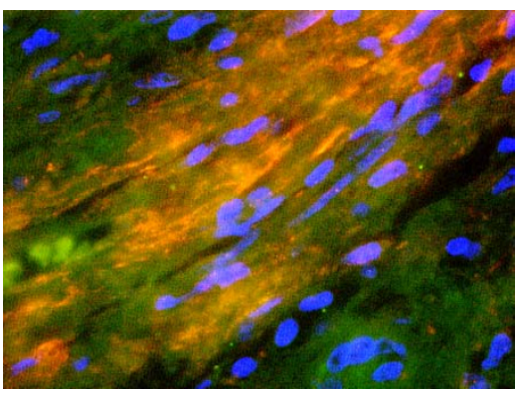

D

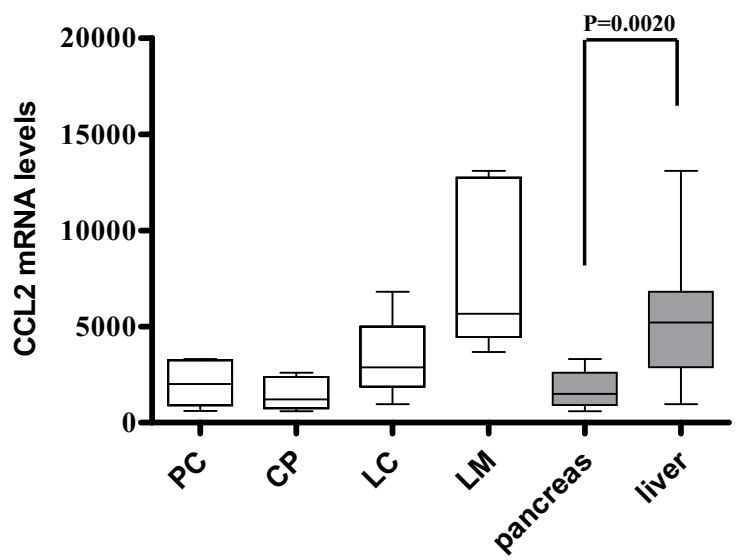

$\mathbf{E}$

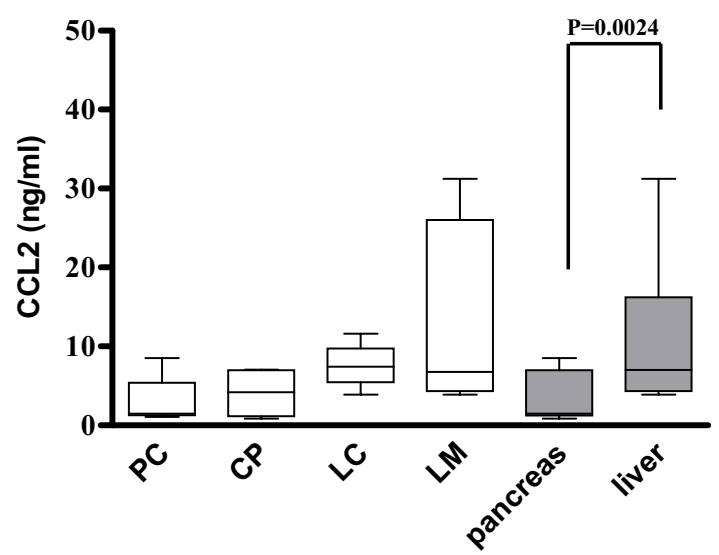

Figure 8 Co-localization of alpha smooth muscle-actin and VCAM1 molecules in hepatic stellate cells and quantitative mRNA and protein expression analysis of CCL2. In liver cirrhosis tissues, immunohistochemisty analysis was performed with antibodies against a-SMA ( $\mathrm{A}, 400 \mathrm{X}$ ) and VCAM1 $(B, 400 \times)$. Double-staining and ex vivo immunofluorescence analysis was used to evaluate the co-localization (orange) of the typical stellate cell marker a-SMA (red) and VCAM-1 (green) in activated stellate cells of liver cirrhosis tissues (C, 630X). Quantitative real-time PCR (A) was performed with the Light Cycler Fast Start DNA SYBR Green kit. (B) A commercial ELISA kit was used to measure the CCL2 protein in the cell lysates of cultured stellate cells. The disease specific expression of CCL2 is depicted in the last two columns of each graph.

therefore a weakness of the past studies might be the limited number of patients' stellate cells investigated to cover the inter-individual heterogeneity. Our report constitute one of the most comprehensive studies on stellate cell transcriptome using 22 different human donors, thus diminishing potential patient specific biases. This might be a plausible explanation for the success of our approach to identify organ- and disease-specific stellate cell transcriptome. In contrast to the studies comparing quiescent vs. activated stellate cells, we compared human stellate cells that were activated in-vivo either by chronic inflammation or cancer. Currently there is no information on how the "ancestral microenvironmental activity" of stellate cells affects their transcriptome after in-vitro cultivation. Therefore, the identified tumor stellate cell specific genes e.g. CELSR3 might provide a favorable therapeutic profile to selectively target tumor stroma while sparing the stellate cell activity under physiological conditions.
It has been reported that experimental ablation of tumor associated fibroblasts or down-regulation of the hedgehog-signalling pathway in the pancreatic tumor stroma decreased cancer cell growth and greatly increased intra-tumoral uptake of chemotherapeutic drugs in murine models of colon, breast cancer an pancreatic cancers $[5,35]$. It is likely that targeting the stroma in order to uncouple stromal-cancer cell interactions may interrupt multiple aberrant autocrine and paracrine pathways that promote pancreatic cancer cell growth, invasion and metastasis [4,21]. Currently, there is no stellate cell specific promoter known to specifically target the stromal cells in the liver or pancreas. Moreover, the similarities between PSC and HSC make it very difficult to target one population without creating side-effects on the other one. For example, the usage of retinoids seems promising in deactivating PSC in-vitro [36]. In contrast, treatment with retinoids were shown to provoke fibro- 
Table 3: A group of highly differentially expressed genes between inflammation and cancer-associated stellate cells are shown.

\begin{tabular}{|c|c|c|}
\hline Gene Name Description & RefSeq ID & Fold-change \\
\hline \multicolumn{3}{|c|}{ DISEASE-SPECIFIC DIFFERENCES IN GENE EXPRESSION } \\
\hline \multicolumn{3}{|c|}{ Tumor specific transcripts (High in tumor compared to inflammation) } \\
\hline $\begin{array}{l}\text { CELSR3 cadherin, EGF LAG seven-pass G- } \\
\text { type receptor } 3\end{array}$ & NM_001407 & 3.04 \\
\hline SYT13 synaptotagmin XIII & NM_020826 & 3.04 \\
\hline CLCN3 chloride channel 3 & NM_001829 & 2.69 \\
\hline RTN4RL1 reticulon 4 receptor-like 1 & NM_178568 & 2.45 \\
\hline METAP2 methionyl aminopeptidase 2 & NM_006838 & 2.11 \\
\hline $\begin{array}{l}\text { PARD3 par-3 partitioning defective } 3 \\
\text { homolog (C. elegans) }\end{array}$ & NM_019619 & 2.00 \\
\hline SYK spleen tyrosine kinase & NM_001135052 & 1.94 \\
\hline $\begin{array}{l}\text { JAK2 Janus kinase } 2 \text { (a protein tyrosine } \\
\text { kinase) }\end{array}$ & NM_004972 & 1.93 \\
\hline
\end{tabular}

\begin{tabular}{|c|c|c|}
\hline \multicolumn{3}{|c|}{ Inflammation specific transcripts (High in inflammation compared to tumor) } \\
\hline $\begin{array}{l}\text { PTPRC protein tyrosine phosphatase, } \\
\text { receptor type, C }\end{array}$ & NM_001846 & 2.61 \\
\hline DHODH dihydroorotate dehydrogenase & NM_001361 & 2.56 \\
\hline KIAA0773 KIAA0773 gene product & NM_001031690 & 2.38 \\
\hline COL4A2 collagen, type IV, alpha 2 & NM_001846 & 2.31 \\
\hline $\begin{array}{l}\text { PBX1 pre-B-cell leukemia transcription } \\
\text { factor } 1\end{array}$ & NM_002585 & 1.70 \\
\hline RBP2 retinol binding protein 2 , cellular & NM_004164 & 1.66 \\
\hline HPX hemopexin & NM_000613 & 1.64 \\
\hline CCL5 chemokine (C- $\mathrm{C}$ motif) ligand 5 & NM_002985 & 1.63 \\
\hline
\end{tabular}




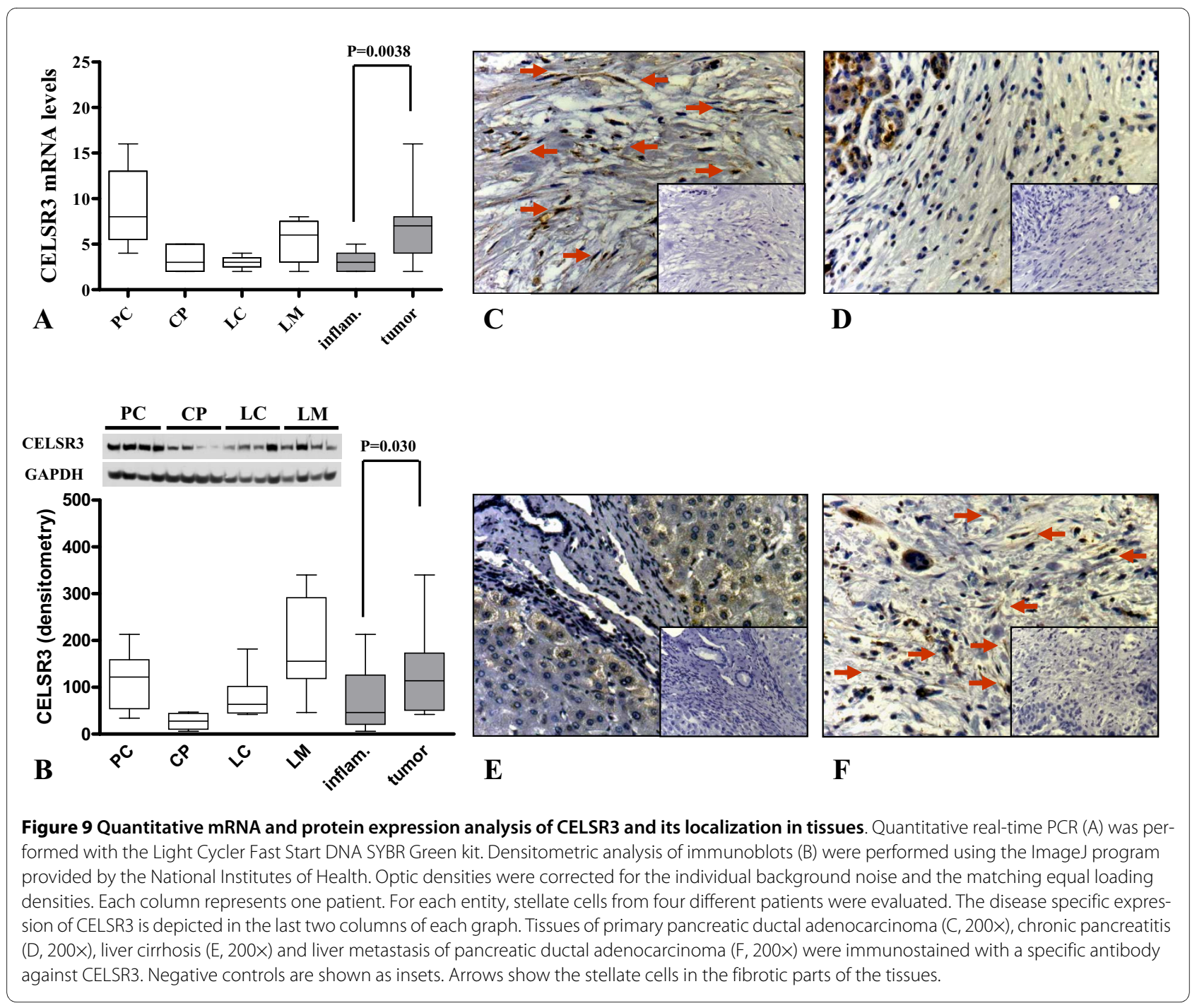

genic effects in HSC, thus, limiting its efficient systemic use in the clinical setting [37].

In this context, our data provide valuable information focusing on the subtle but important differences of liver vs. pancreatic stellate cells that exist rather than their similarities. We found collagen type 11a1 expression to be highly specific for the PSC and almost absent in HSC. Type XI collagen is a minor fibril-forming collagen that assists in proper type II collagen fibril formation [38]. Col11a1 is mainly expressed in articular cartilage and the vitreous fluid of the eye [39-43]. During embryogenesis, Col11a1 expression is also detectable in many other human fetal tissues including the bone [40]. Marshall and type II Stickler syndromes are genetically transmitted diseases that are caused by mutations in Col11a1 gene manifested with sensory and skeletal abnormalities $[44,45]$. In Col11a1 knockout mice, chondrocytes fail to fully differentiate causing a chondrodystrophic phenotype with skeletal abnormalities. These data show that Col11a1 is essential for skeletal morphogenesis because it controls type II collagen fibrillogenesis, chondrocyte maturation and bone mineralization [46,47]. Importantly, in adult life these tissues are not undergoing dynamic changes. Therefore Coll11a1 may provide an interesting target for conditional knockout to target PSC in order to assess PSC contribution in conditions like chronic pancreatitis or pancreatic cancer.

Buchholz et al. compared gene expression of human HSC, PSC and skin fibroblasts [9]. Their data show that, compared to dermal fibroblasts, HSC and PSC exhibit great similarities in their transcriptional phenotypes and possibly share a common origin [3,9]. Indeed, HSC and PSC are activated by common cytokines, growth factors and alcohol metabolites during development of tissue fibrosis $[3,7,30,48-50]$. However, the fundamental differences in their microenvironments may condition these cells to differentially respond to organ injury and cancer $[1,3,30]$. For example, in contrast to hepatocellular carci- 


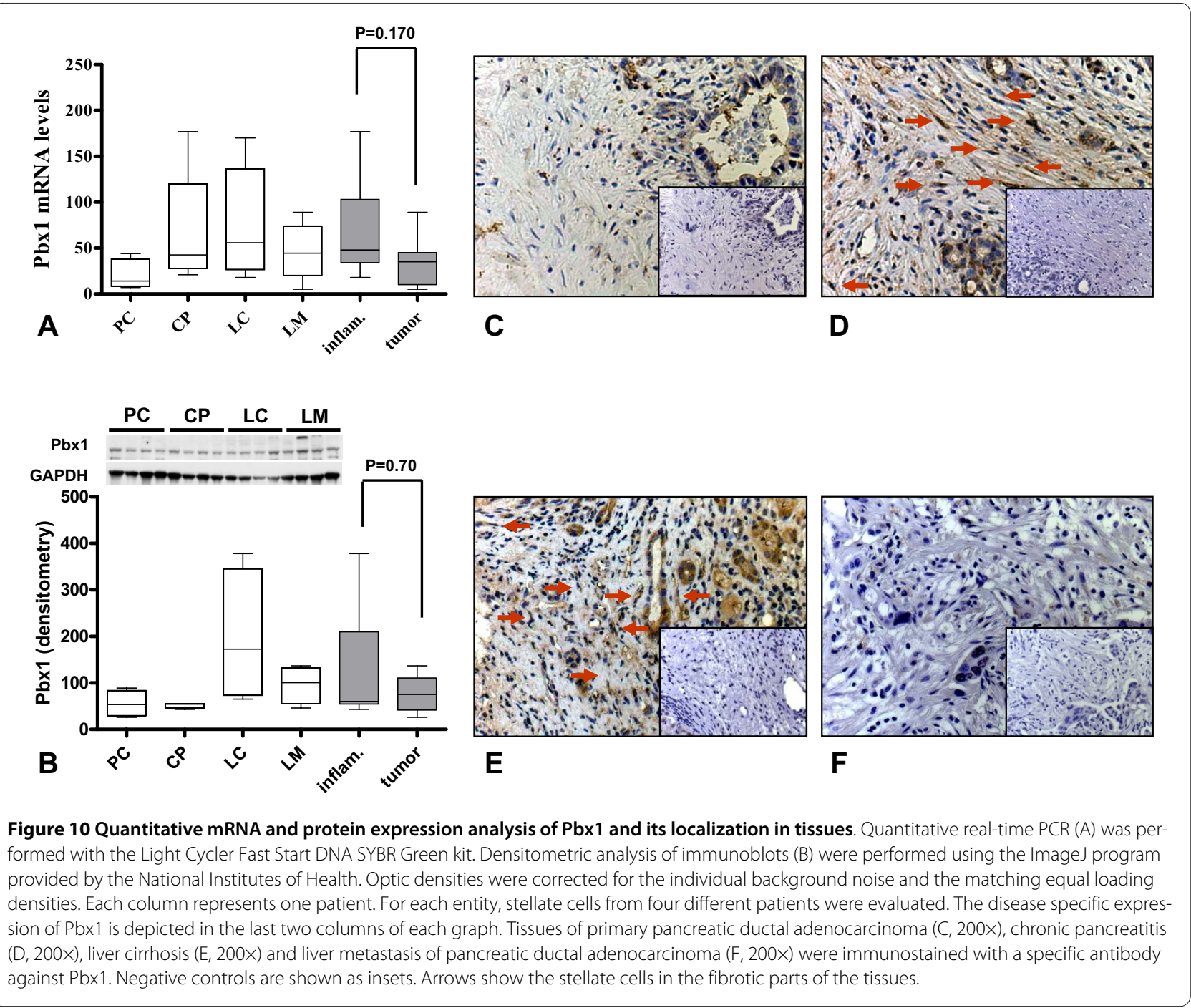

noma, desmoplasia is a typical feature of pancreatic ductal adenocarcinoma. This difference may result in part due to the release of potent fibrogenic mediators by pancreatic cancer cells $[1,19,30,51]$. We have previously shown that, compared to the primary tumor, liver metastasis of PDAC elicit a weaker fibrogenic response in the HSC that surround them. This observation can be due to the differences of HSC and PSC, or it could, considering the temporal sequence of events, merely reflect a shorter cancer-HSC interaction [30]. Interestingly, we found almost twice as much differentially regulated genes with an organ specific expression pattern as compared to chronic inflammation or tumor related genes. Moreover, differences in gene expression levels between HSC and PCS were more pronounced compared to disease specific stellate cells. These differences can be due to various factors. It may reflect that PSC and HSC do not share a common origin, or it may also suggest that chronic inflammation and cancer develop in similar microenvironments created by the activated stroma of the respective organs.

In the clinical setting, chronic inflammatory conditions of the liver (cirrhosis) and pancreas (chronic pancreatitis) not only increase the incidence of cancer, but also constitute diagnostic hurdles. Biopsies that do not show tumor structures are not helpful in diagnosis since they are useless in exclusion of the tumor. However, identification of tumor versus inflammation specific signatures of the stroma may increase diagnostic accuracy of biopsies even where tumor tissue is missed.

Conclusively, identification of inherent and acquired differences in stellate cell transcriptome will improve current understanding of stellate cell pathophysiology and may facilitate the discovery of novel selective therapeutic targets. Our data provide a new platform to understand and possibly interfere with organ or disease specific 
responses of stellate cells. Further research is warranted to analyze the importance of these findings at functional levels.

\section{Conflict of interests}

The authors declare that they have no competing interests.

\section{Additional material}

\section{Additional file 1 Expression profile of stellate cells for typical mark-}

ers. The purity of the stellate cell population was routinely checked by immunocytochemistry and immunofluorescence analyses at every passage used. Cells were seeded on Teflon covered slides, fixed, permeabilized and immunostained with specific antibodies against a-SMA, collagen type-la, fibronectin, periostin, collagen XVIII and VEGF as published before [30]. Contamination profiling for cancer cells was made by a specific antibody against Pan-cytokeratin. Non-immunized lgG was used appropriately as negative control (original magnification: 200-400x).

\section{Abbreviations}

CP: Chronic pancreatitis; HSC: Hepatic stellate cells; IHC: Immunohistochemistry; LC: Liver cirrhosis; LM: Liver metastasis; PDAC: Pancreatic ductal adenocarcinoma; PSC: Pancreatic stellate cells.

\section{Authors' contributions}

Study concept and design: ME, HF, JD, PEH, AA, JK; acquisition of data: NW, TS ZP, CS, XJ, UW, NAG, WA; analysis and interpretation of data: ME, CS, WA, AA, JK drafting of the manuscript: $M E, A A, J K$; critical revision of the manuscript for important intellectual content JD, PEH, HF; statistical analysis: CS; obtained funding: NAG, PEH, AA, ME, JK; technical and material support: NAG, JD; study supervision: AA, JK. All authors have read and approved the final manuscript.

\section{Acknowledgements}

This work was supported in part by National Aeronautics and Space Administration Specialized Center of Research NNJ04HJ12G, German Krebshilfe (Deutsche Krebshilfe, 107691), DFG National Priority Research Program the Tumor-Vessel Interface "SPP1190", Dietmar Hopp Stiftung awarded to JK and NAG, 03NUK004A/C and by a grant from the German Federal Ministry of Education and Research (Bundesministerium für Bildung und Forschung - BMBF ME and JK) within the "National Genome Research Network" (NGFN-Plus; 01GS08115)

We thank Barbara Schwager and Claudia Rittmüller for their excellent technical assistance with the microarray analysis.

\section{Author Details}

'Department of General Surgery, Technische Universität München, Munich, Germany, ${ }^{2}$ Department of Radiation Oncology, German Cancer Research Center (DKFZ) and University of Heidelberg, Heidelberg, Germany, 3Department of General Surgery, University of Heidelberg, Heidelberg, Germany, ${ }^{4}$ Center of Cancer Systems Biology, Dept. of Medicine, Caritas St. Elizabeth's Medical Center, Tufts University School of Medicine, Boston, Massachusetts 02135-2997, USA and 5Children's Hospital Boston, Vascular Biology Program \& Harvard Medical School, Department of Surgery, Karp Family Research Laboratories, Boston, Massachusetts 02115, USA

Received: 14 September 2009 Accepted: 23 April 2010 Published: 23 April 2010

\section{References}

1. Friedman SL: Hepatic stellate cells: protean, multifunctional, and enigmatic cells of the liver. Physiol Rev 2008, 88:125-172.

2. Friedman SL: Mechanisms of hepatic fibrogenesis. Gastroenterology 2008, 134:1655-1669.

3. Omary MB, Lugea A, Lowe AW, Pandol SJ: The pancreatic stellate cell: a star on the rise in pancreatic diseases. J Clin Invest 2007, 117:50-59.

4. Erkan M, Reiser-Erkan C, Michalski CW, Deucker S, Sauliunaite D, Streit S, Esposito I, Friess H, Kleeff J: Cancer-stellate cell interactions perpetuate the hypoxia-fibrosis cycle in pancreatic ductal adenocarcinoma. Neoplasia 2009, 11:497-508.

5. Olive KP, Jacobetz MA, Davidson CJ, Gopinathan A, Mclntyre D, Honess D, Madhu B, Goldgraben MA, Caldwell ME, Allard D, et al:: Inhibition of Hedgehog signaling enhances delivery of chemotherapy in a mouse model of pancreatic cancer. Science 2009, 324:1457-1461.

6. Watari N, Hotta Y, Mabuchi Y: Morphological studies on a vitamin Astoring cell and its complex with macrophage observed in mouse pancreatic tissues following excess vitamin A administration. Okajimas Folia Anat Jpn 1982, 58:837-858.

7. Apte MV, Haber PS, Applegate TL, Norton ID, McCaughan GW, Korsten MA, Pirola RC, Wilson JS: Periacinar stellate shaped cells in rat pancreas: identification, isolation, and culture. Gut 1998, 43:128-133.

8. Bachem MG, Schneider E, Gross H, Weidenbach H, Schmid RM, Menke A, Siech M, Beger H, Grunert A, Adler G: Identification, culture, and characterization of pancreatic stellate cells in rats and humans. Gastroenterology 1998, 115:421-432.

9. Buchholz M, Kestler HA, Holzmann K, Ellenrieder V, Schneiderhan W, Siech M, Adler G, Bachem MG, Gress TM: Transcriptome analysis of human hepatic and pancreatic stellate cells: organ-specific variations of a common transcriptional phenotype. J Mol Med 2005, 83:795-805.

10. Asahina K, Tsai SY, Li P, Ishii M, Maxson RE Jr, Sucov HM, Tsukamoto H: Mesenchymal origin of hepatic stellate cells, submesothelial cells, and perivascular mesenchymal cells during mouse liver development. Hepatology 2008.

11. Enzan H, Himeno H, Hiroi M, Kiyoku H, Saibara T, Onishi S: Development of hepatic sinusoidal structure with special reference to the Ito cells. Microsc Res Tech 1997, 39:336-349.

12. Kiassov AP, Van Eyken P, van Pelt JF, Depla E, Fevery J, Desmet VJ, Yap SH: Desmin expressing nonhematopoietic liver cells during rat liver development: an immunohistochemical and morphometric study. Differentiation 1995, 59:253-258.

13. Vassy J, Rigaut JP, Briane D, Kraemer M: Confocal microscopy immunofluorescence localization of desmin and other intermediate filament proteins in fetal rat livers. Hepatology 1993, 17:293-300.

14. Cassiman D, Roskams T: Beauty is in the eye of the beholder: emerging concepts and pitfalls in hepatic stellate cell research. J Hepatol 2002, 37:527-535

15. Friedman SL: Molecular regulation of hepatic fibrosis, an integrated cellular response to tissue injury. J Biol Chem 2000, 275:2247-2250.

16. Niki T, Pekny M, Hellemans K, Bleser PD, Berg KV, Vaeyens F, Quartier E, Schuit F, Geerts A: Class VI intermediate filament protein nestin is induced during activation of rat hepatic stellate cells. Hepatology 1999, 29:520-527.

17. Geerts A: On the origin of stellate cells: mesodermal, endodermal or neuro-ectodermal? J Hepatol 2004, 40:331-334.

18. Erkan M, Michalski CW, Rieder S, Reiser-Erkan C, Abiatari I, Kolb A, Giese $\mathrm{NA}$, Esposito I, Friess $\mathrm{H}$, Kleeff J: The activated stroma index is a novel and independent prognostic marker in pancreatic ductal adenocarcinoma. Clin Gastroenterol Hepatol 2008, 6:1155-1161.

19. Bachem MG, Schunemann M, Ramadani M, Siech M, Beger H, Buck A, Zhou S, Schmid-Kotsas A, Adler G: Pancreatic carcinoma cells induce fibrosis by stimulating proliferation and matrix synthesis of stellate cells. Gastroenterology 2005, 128:907-921.

20. Vonlaufen A, Xu Z, Daniel B, Kumar RK, Pirola R, Wilson J, Apte MV: Bacterial endotoxin: a trigger factor for alcoholic pancreatitis? Evidence from a novel, physiologically relevant animal model. Gastroenterology 2007, 133:1293-1303.

21. Abdollahi A, Hlatky L, Huber PE: Endostatin: the logic of antiangiogenic therapy. Drug Resist Updat 2005, 8:59-74.

22. Michalski CW, Erkan M, Sauliunaite D, Giese T, Stratmann R, Sartori C, Giese $N A$, Friess $H$, Kleeff J: Ex vivo chemosensitivity testing and gene expression profiling predict response towards adjuvant gemcitabine treatment in pancreatic cancer. Br J Cancer 2008, 99:760-767.

23. Domhan S, Zeier M, Abdollahi A: Immunosuppressive therapy and posttransplant malignancy. Nephrol Dial Transplant 2008.

24. Abdollahi A, Schwager C, Kleeff J, Esposito I, Domhan S, Peschke P, Hauser K, Hahnfeldt P, Hlatky L, Debus J, et al.: Transcriptional network governing the angiogenic switch in human pancreatic cancer. Proc Natl Acad Sci USA 2007, 104:12890-12895

25. Li J, Kleeff J, Kayed H, Felix K, Penzel R, Buchler MW, Korc M, Friess H: Glypican-1 antisense transfection modulates TGF-beta-dependent 
signaling in Colo-357 pancreatic cancer cells. Biochem Biophys Res Commun 2004, 320:1148-1155.

26. Domhan S, Muschal S, Schwager C, Morath C, Wirkner U, Ansorge W Maercker C, Zeier M, Huber PE, Abdollahi A: Molecular mechanisms of the antiangiogenic and antitumor effects of mycophenolic acid. Mol Cancer Ther 2008, 7:1656-1668.

27. Abdollahi A, Hahnfeldt P, Maercker C, Grone HJ, Debus J, Ansorge W, Folkman J, Hlatky L, Huber PE: Endostatin's antiangiogenic signaling network. Mol Cell 2004, 13:649-663.

28. Erkan M, Kleeff J, Esposito I, Giese T, Ketterer K, Buchler MW, Giese NA, Friess H: Loss of BNIP3 expression is a late event in pancreatic cancer contributing to chemoresistance and worsened prognosis. Oncogene 2005, 24:4421-4432.

29. Reiser-Erkan C, Erkan M, Pan Z, Bekasi S, Giese NA, Streit S, Michalski CW, Friess $\mathrm{H}$, Kleeff J: Hypoxia-inducible proto-oncogene Pim-1 is a prognostic marker in pancreatic ductal adenocarcinoma. Cancer Biol Ther 2008, 7:1352-1359.

30. Erkan M, Kleeff J, Gorbachevski A, Reiser C, Mitkus T, Esposito I, Giese T, Buchler MW, Giese NA, Friess H: Periostin creates a tumor-supportive microenvironment in the pancreas by sustaining fibrogenic stellate cell activity. Gastroenterology 2007, 132:1447-1464.

31. Kota J, Caceres N, Constantinescu SN: Aberrant signal transduction pathways in myeloproliferative neoplasms. Leukemia 2008, 22:1828-1840

32. McCubrey JA, Steelman LS, Abrams SL, Bertrand FE, Ludwig DE, Basecke J, Libra M, Stivala F, Milella M, Tafuri A, et al:: Targeting survival cascades induced by activation of Ras/Raf/MEK/ERK, PI3K/PTEN/Akt/mTOR and Jak/STAT pathways for effective leukemia therapy. Leukemia 2008, 22:708-722.

33. Katoh M: WNT/PCP signaling pathway and human cancer (review). Oncol Rep 2005, 14:1583-1588.

34. Wu Q, Maniatis T: Large exons encoding multiple ectodomains are a characteristic feature of protocadherin genes. Proc Natl Acad Sci USA 2000, 97:3124-3129.

35. Loeffler M, Kruger JA, Niethammer AG, Reisfeld RA: Targeting tumorassociated fibroblasts improves cancer chemotherapy by increasing intratumoral drug uptake. J Clin Invest 2006, 116:1955-1962.

36. Jaster R, Hilgendorf I, Fitzner B, Brock P, Sparmann G, Emmrich J, Liebe S: Regulation of pancreatic stellate cell function in vitro: biological and molecular effects of all-trans retinoic acid. Biochem Pharmacol 2003, 66:633-641.

37. Pinzani M: Pancreatic stellate cells: new kids become mature. Gut 2006, 55:12-14

38. Gelse K, Poschl E, Aigner T: Collagens--structure, function, and biosynthesis. Adv Drug Deliv Rev 2003, 55:1531-1546.

39. Iyama K, Sumiyoshi H, Khaleduzzaman M, Matsuo N, Ninomiya Y, Yoshioka $\mathrm{H}$ : Differential expression of two exons of the alpha1 $(\mathrm{XI})$ collagen gene (Col11a1) in the mouse embryo. Matrix Biol 2001, 20:53-61.

40. Lui VC, Kong RY, Nicholls J, Cheung AN, Cheah KS: The mRNAs for the three chains of human collagen type $\mathrm{XI}$ are widely distributed but not necessarily co-expressed: implications for homotrimeric, heterotrimeric and heterotypic collagen molecules. Biochem J 1995, 311(Pt 2):511-516.

41. So CL, Kaluarachchi K, Tam PP, Cheah KS: Impact of mutations of cartilage matrix genes on matrix structure, gene activity and chondrogenesis. Osteoarthritis Cartilage 2001, 9(Suppl A):S160-173.

42. Yoshioka H, Greenwel P, Inoguchi K, Truter S, Inagaki Y, Ninomiya Y, Ramirez F: Structural and functional analysis of the promoter of the human alpha 1 (XI) collagen gene. J Biol Chem 1995, 270:418-424.

43. Yoshioka H, Iyama K, Inoguchi K, Khaleduzzaman M, Ninomiya Y, Ramirez F: Developmental pattern of expression of the mouse alpha 1 (XI) collagen gene (Col11a1). Dev Dyn 1995, 204:41-47.

44. Annunen S, Korkko J, Czarny M, Warman ML, Brunner HG, Kaariainen H, Mulliken JB, Tranebjaerg L, Brooks DG, Cox GF, et al:: Splicing mutations of 54-bp exons in the COL11A1 gene cause Marshall syndrome, but other mutations cause overlapping Marshall/Stickler phenotypes. Am J Hum Genet 1999, 65:974-983.

45. Griffith AJ, Sprunger LK, Sirko-Osadsa DA, Tiller GE, Meisler MH, Warman ML: Marshall syndrome associated with a splicing defect at the COL11A1 locus. Am J Hum Genet 1998, 62:816-823.
46. Li Y, Lacerda DA, Warman ML, Beier DR, Yoshioka H, Ninomiya Y, Oxford JT, Morris NP, Andrikopoulos K, Ramirez F, et al:: A fibrillar collagen gene,

Col11a1, is essential for skeletal morphogenesis. Cell 1995, 80:423-430.

47. Seegmiller R, Fraser FC, Sheldon $\mathrm{H}$ : A new chondrodystrophic mutant in mice. Electron microscopy of normal and abnormal chondrogenesis. $J$ Cell Biol 1971, 48:580-593.

48. Michalski CW, Gorbachevski A, Erkan M, Reiser C, Deucker S, Bergmann F, Giese T, Weigand M, Giese NA, Friess H, Kleeff J: Mononuclear cells modulate the activity of pancreatic stellate cells which in turn promote fibrosis and inflammation in chronic pancreatitis. J Trans/ Med 2007, 5:63.

49. Michalski CW, Maier M, Erkan M, Sauliunaite D, Bergmann F, Pacher P, Batkai S, Giese NA, Giese T, Friess H, Kleeff J: Cannabinoids reduce markers of inflammation and fibrosis in pancreatic stellate cells. PLOS ONE 2008, 3:e1701.

50. Apte MV, Haber PS, Darby SJ, Rodgers SC, McCaughan GW, Korsten MA, Pirola RC, Wilson JS: Pancreatic stellate cells are activated by proinflammatory cytokines: implications for pancreatic fibrogenesis. Gut 1999, 44:534-541.

51. Bachem MG, Zhou Z, Zhou S, Siech M: Role of stellate cells in pancreatic fibrogenesis associated with acute and chronic pancreatitis. J Gastroenterol Hepatol 2006, 21(Suppl 3):S92-96.

doi: $10.1186 / 1476-4598-9-88$

Cite this article as: Erkan et al., Organ-, inflammation- and cancer specific transcriptional fingerprints of pancreatic and hepatic stellate cells Molecular Cancer 2010, $9: 88$

\section{Submit your next manuscript to BioMed Central and take full advantage of:}

- Convenient online submission

- Thorough peer review

- No space constraints or color figure charges

- Immediate publication on acceptance

- Inclusion in PubMed, CAS, Scopus and Google Scholar

- Research which is freely available for redistribution

Submit your manuscript at www.biomedcentral.com/submit
C) Biomed Central 